\title{
Evaluation of TRMM Multi-satellite precipitation analysis (TMPA) in the Yangtze River basin
}

\author{
Qiu Jin ${ }^{1, a}$, Zengxin Zhang ${ }^{1, b^{*}}$, Yuhan Huang ${ }^{1, c}$ \\ 1. Joint Innovation Center for Modern Forestry Studies, College of Biology and the Environment, \\ Nanjing Forestry University, Nanjing, Jiangsu, China, 210037

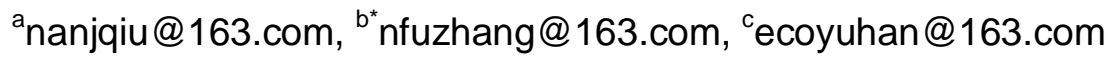

\begin{abstract}
Key words: TRMM 3B42; Yangtze River basin; precipitation
Abstract. As the Tropical Rainfall Measuring Mission (TRMM) satellite completes more than a decade of operation, it has provided researchers throughout the world with a large volume of rainfall data. The Yangtze River is the longest river in China, it plays an important role in the regional water cycle, energy balance and ecosystems. In this paper, we use different rainfall accuracy estimation indexes to estimate the precision of precipitation data gained from TRMM satellite in the Yangtze River basin according to the gauge rain data. The results indicate that: 1) 3B42 V7 has a good precision in application to the Yangtze River basin. 3B42 RTV7 can also capture the spatial distribution of annual precipitation. 2) TMPA products have a higher estimate precision in the mid-lower Yangtze reaches compared to the upper Yangtze reaches. 3) Both 3B42 RTV7 and 3B42 V7 apply better in the flood period than the low water period.
\end{abstract}

\section{Introduction}

Accurate precipitation data at high spatial and temporal resolution is deemed necessary for various fields of research, such as meteorological disaster prevention, climate change and water resources management [1]. Although surface precipitation gauges are considered the standard for measuring precipitation, the rainfall gauge network is still insufficient across significant areas worldwide, and the remotely sensed information about rainfall becomes the only source of reliable data[2]. Thus satellite-based precipitation products are expected to offer an alternative to ground-based rainfall estimates in the present and the foreseeable future[3]. For this purpose, the quality and usefulness of satellite-based precipitation products need to be evaluated.

Satellite-based precipitation products offer a potential alternative or supplement to rainfall estimates over sparsely gauged or ungauged basins[4]. As the Tropical Rainfall Measuring Mission (TRMM) satellite completes more than a decade of operation, it has provided researchers throughout the world rainfall data for the validation of atmospheric and climate models. The TRMM products studied are the near-real-time products 3B42RT Version 7 (hereafter 3B42 RTV7) estimates and research products 3B42 Version 7 (hereafter 3B42 V7) estimates.

In recent years, the comparison has been made between the TRMM Multi Satellite Product 3B42 and rain gauge observations in the world. Chen et al [5] showed that the TRMM 3B42RT rainfall data has a high precision with the observed precipitation in the humid subtropical Pearl River basin, China. Zhao et al [6] also found that there was good linear relationship between TRMM 3B42 V7 and rain gauge data in Weihe River catchment, Yellow River basin. However, Habib and Henschke[7] reported that the TMPA products tend to overestimate small rain rates and underestimate large rain rates over Louisiana, USA. Li et al [8] reported that daily TRMM rainfall data does not describe the occurrence and contribution rates of precipitation accurately in Poyang Lake basin, China.

The Yangtze has been subjected to flooding throughout history. In 1998, the entire Yangtze drainage area suffered from tremendous flooding, the largest flood since 1954, which lead to the economic loss of 166 billion Yuan (US \$20 billion)[9]. Although there are hundreds of gauge stations in the Yangtze River basin, the gauge network is still insufficient in the Yangtze River basin especially in the upper Yangtze reaches due to its high elevation and complex terrain. Additionally, the most widely used rain gauge stations are distributed sparsely and unevenly.

This paper uses different rainfall accuracy estimation indexes to estimate the precision of 
precipitation data gained from TRMM satellite in the Yangtze River basin according to the gauge rain data.

\section{Data and Method}

Study area

The Yangtze River is the longest river in China and the third longest in the world. The river is about $6300 \mathrm{~km}$ long and the basin lies between latitudes $24^{\circ} \mathrm{N}$ and $36^{\circ} \mathrm{N}$ and longitudes $90^{\circ} \mathrm{E}$ and $122.5^{\circ} \mathrm{E}$. The Yangtze River originates from Qinghai Province, with its mainstream flowing across 11 provinces of China. The Yangtze River basin is one of the largest river basins in the world with an area of $\sim 1,800,000 \mathrm{~km}^{2}$ that accounts for $\sim$ one fifth of China's territory. Fig. 1 shows the location of the Yangtze River basin and 175 gauge stations.

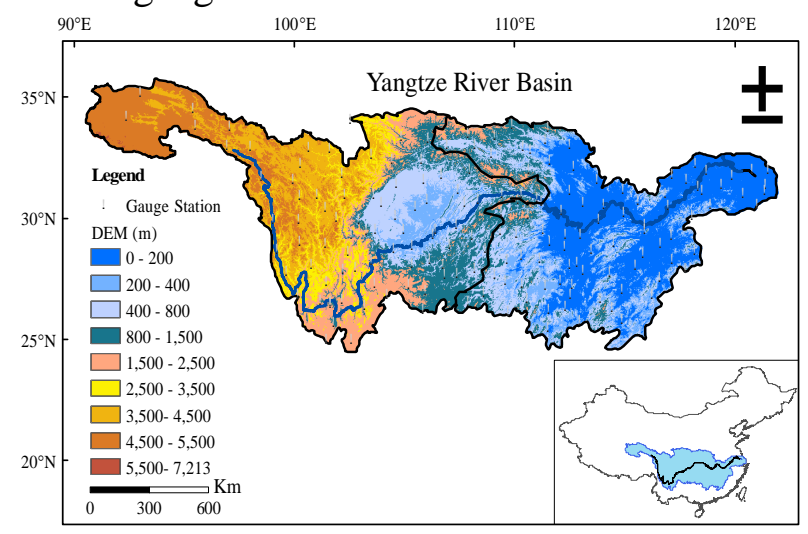

Fig.1 Location of the Yangtze River basin and gauge stations.

Precipitation data

The 3B42 TMPA datasets used in this study were downloaded from the NASA website (http://trmm.gsfc.nasa.gov/). It has a high temporal (3h) and spatial $\left(0.25^{\circ} \times 0.25^{\circ}\right)$ resolution. The 3B42 TMPA dataset is available in two versions: a research-quality product (3B42) released 10-15 days after each month and a near-real-time product (3B42 RT), which is released approximately $9 \mathrm{~h}$ after real-time. Eight years (2003-2010) of daily rainfall data from 175 rain gauge stations in the Yangtze River basin were compared with the TRMM rainfall data to evaluate the quality of TRMM rainfall estimates at different spatial and temporal scales.

Statistical indices

The relative Bias $(\%)$ is used to measure the agreement between the averaged value of TMPA data and observed data.

$$
\text { Bias }=\left[\frac{\sum_{i=1}^{n} \operatorname{Sim}_{i}-\sum_{i=1}^{n} O b s_{i}}{\sum_{i=1}^{n} O b s_{i}}\right] \times 100
$$

\section{Results}

Evaluation of annual mean precipitation from TMPA products

Fig.2 shows the spatial distribution of annual mean precipitation in Yangtze River basin from TMPA and observed data from 2003 to 2010. Annual precipitation from observed data exhibits a southeast to northwest gradient, ranging from over $2000 \mathrm{~mm} / \mathrm{year}$ in the southeast to less than 400 $\mathrm{mm} /$ year in the northwest (Fig.2a). 3B42 RTV7 can capture the spatial distribution of annual precipitation, however, the tendency of overestimation especially in the upper Yangtze reaches in the plateau section is clearly visible (Fig. 2b). The annual spatial variations of the 3B42 V7 is similar to observed data (Fig.2c). 3B42 V7 is reliable and has a good precision in the Yangtze River basin. 
(a) Obs

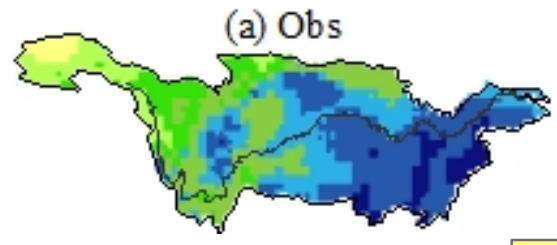

(b) 3 B42 RTV7

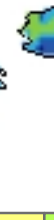

$4006008001000120016002000(\mathrm{~mm})$

(c) $3 \mathrm{~B} 42 \mathrm{~V} 7$

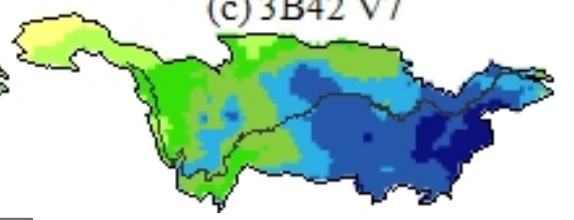

Fig.2 Spatial distribution of annual mean precipitation in Yangtze River basin from TMPA and Observed data from 2003 to 2010.

Distribution of bias for estimated from TMPA in the upper Yangtze, mid-lower Yangtze and the whole Yangtze is shown in Table.1. The bias of 3B42 V7 estimate mostly distributes between $-10 \%$ and $10 \%$ (Table.1). It overall exhibits small bias in the Yangtze River basin compared with real-time products 3B42 RTV7. Large positive bias dominates in the Yangtze River basin from 3B42 RTV7, 50.49\% of the whole Yangtze shows a positive bias more than 10\%.TMPA products applied better in the mid-lower Yangtze compared to the upper Yangtze.

Table.1 Distributions of bias for estimated from TMPA in the Upper Yangtze, Mid-lower Yangtze and the Whole Yangtze

\begin{tabular}{ccccccccc}
\hline & Type & $<-50$ & $-50--31$ & $-30--11$ & $-10-10$ & $11-30$ & $31-50$ & $>50$ \\
\hline the Upper & RTV7 & 0.13 & 0.40 & 12.81 & 24.88 & 20.50 & 7.75 & 33.51 \\
\cline { 2 - 9 } Yangtze & V7 & 0.13 & 2.90 & 31.09 & 52.66 & 12.88 & 0.27 & 33.51 \\
\hline Mid-lower & RTV7 & 0 & 0.51 & 11.63 & 51.47 & 30.50 & 5.64 & 0.25 \\
\cline { 2 - 9 } Yangtze & V7 & 0 & 0.17 & 12.89 & 68.83 & 18.08 & 0.08 & 0 \\
\hline the Whole & RTV7 & 0.07 & 0.45 & 12.28 & 36.70 & 24.94 & 6.82 & 18.73 \\
\cline { 2 - 9 } Yangtze & V7 & 0.07 & 1.69 & 23.00 & 59.85 & 15.17 & 0.19 & 0.04 \\
\hline
\end{tabular}

Evaluation of precipitation from TMPA products in month scale

Time-series of mean monthly precipitation in the Yangtze River basin is shown in Fig.3. The upper Yangtze reaches precipitation peak value in July. The mid-lower Yangtze reaches precipitation peak value a month earlier in June because of the influence of East Asian monsoon. It is notable that there is a small peak in the mid-lower Yangtze reaches in November. 3B42V7 agrees well with observed data both in the upper Yangtze reaches and the mid-lower Yangtze reaches. 3B42RTV7 can represent the rise and fall curve of monthly changes, however, the tendency of overestimation is obvious especially in the flood period.
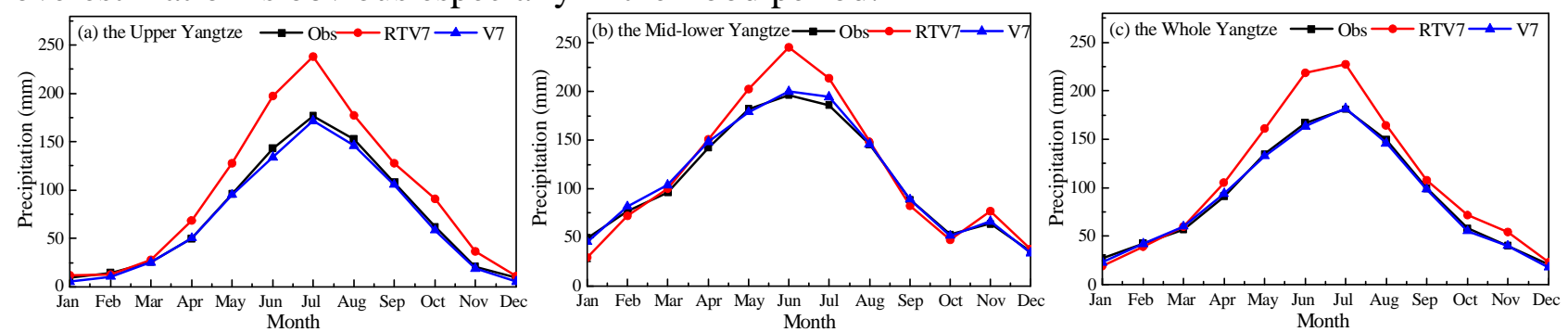

Fig.3 Time-series of mean monthly precipitation (a) the Upper Yangtze, (b) the Mid-lower Yangtze, (c) the Whole Yangtze.
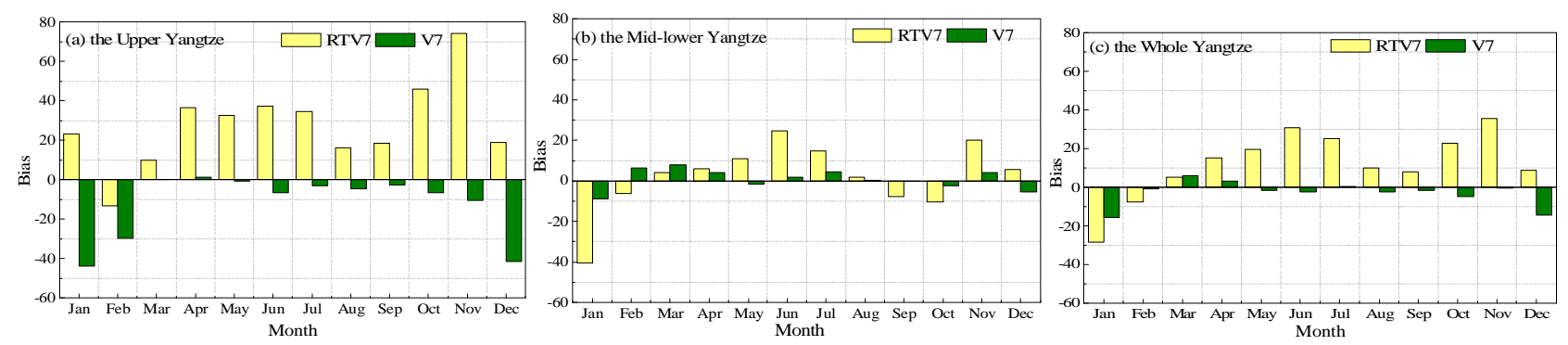

Fig.4 Time-series of bias of mean monthly precipitation (a) the Upper Yangtze, (b) the Mid-lower

Yangtze, (c) the Whole Yangtze. 
Fig.4 exhibits time-series of bias of mean monthly precipitation the upper Yangtze, the mid-lower Yangtze and the whole Yangtze. General overestimation of 3B42 RTV7 exists in most of 12 months especially in the upper Yangtze reaches. Opposite to 3B42 RTV7, 3B42 V7 shows a general underestimation in the upper Yangtze particularly in low water period. TMPA products both real-time product 3B42 RTV7 and research product 3B42 V7 agree better with observed data in the mid-lower Yangtze reaches than in the upper Yangtze reaches.

\section{Conclusions}

This paper uses different rainfall accuracy estimation indexes to estimate the precision of precipitation data gained from TRMM satellite in the Yangtze River basin. The results indicate that:

(1) 3B42 V7 is reliable and had good precision in application to the Yangtze River basin. 3B42 RTV7 can capture the spatial distribution of annual precipitation, however, the tendency of overestimation especially in the upper Yangtze reaches is clearly visible.

(2) TMPA products have a higher estimate precision in the mid-lower Yangtze compared to the upper Yangtze, it probably caused by the high elevation and complex topography in the upper Yangtze.

(3) Both 3B42 RTV7 and 3B42 V7 apply better in the flood period than the low water period in the Yangtze River basin.

\section{References}

[1] S. Pombo, R.P. de Oliveira, Evaluation of extreme precipitation estimates from TRMM in Angola, Journal of Hydrology, 523 (2015) 663-679.

[2] R. Shrivastava, S.K. Dash, M.N. Hegde, K.S. Pradeepkumar, D.N. Sharma, Validation of the TRMM Multi Satellite Rainfall Product 3B42 and estimation of scavenging coefficients for 131I and 137Cs using TRMM 3B42 rainfall data, Journal of Environmental Radioactivity, 138 (2014) 132-136.

[3] X.H. Li, Q. Zhang, C.Y. Xu, Suitability of the TRMM satellite rainfalls in driving a distributed hydrological model for water balance computations in Xinjiang catchment, Poyang lake basin, Journal of Hydrology, 426-427 (2012) 28-38.

[4] J. Meng, L. Li, Z. Hao, J. Wang, Q. Shao, Suitability of TRMM satellite rainfall in driving a distributed hydrological model in the source region of Yellow River, Journal of Hydrology, 509 (2014) 320-332.

[5] C. Chen, Z. Yu, L. Li, C. Yang, Adaptability Evaluation of TRMM Satellite Rainfall and Its Application in the Dongjiang River Basin, Procedia Environmental Sciences, 10, Part A (2011) 396-402.

[6] H. Zhao, S. Yang, Z. Wang, X. Zhou, Y. Luo, L. Wu, Evaluating the suitability of TRMM satellite rainfall data for hydrological simulation using a distributed hydrological model in the Weihe River catchment in China, Journal of Geographical Sciences, 25 (2015) 177-195.

[7] E. Habib, A. Henschke, R.F. Adler, Evaluation of TMPA satellite-based research and real-time rainfall estimates during six tropical-related heavy rainfall events over Louisiana, USA, Atmospheric Research, 94 (2009) 373-388.

[8] X. Li, Q. Zhang, X. Ye, Dry/Wet Conditions Monitoring Based on TRMM Rainfall Data and Its Reliability Validation over Poyang Lake Basin, China, Water, 5 (2013) 1848-1864.

[9] S. Naciri, N. Cheikhrouhou, M. Pouly, J. C. Binggeli, R. Glardon, ERP data sharing framework using the Generic Product Model (GPM), Expert Systems with Applications, 38 (2011) 1203-1212. 